\title{
THE NATURAL HISTORY OF HYDROCEPHALUS
}

\author{
K. M. LaURence, M.A.(Cantab.), M.B., Сн.B.(Liverpool) \\ Senior Lecturer in Paediatric Pathology, Welsh National School of Medicine, Llandough Hospital, Penarth
}

\section{Introduction}

Although hydrocephalus has always been a fascination and a challenge to the medical profession, until the last decade or so the diagnosis and investigation of the condition has been rather an academic exercise. Surgical methods of treatment were not often successful as is suggested by the numerous different forms of treatment introduced and usually abandoned again.

With the gradual elimination of nutritional illnesses and of infective children's diseases due to better prophylactic measures and the use of antibiotics, congenital malformations, the so-called congenital hydrocephalus amongst them, have assumed an increasing importance. Intensive research during the last decade and the development of new plastics have resulted in the introduction of a number of new surgical procedures which now seem to offer a reasonable chance of arresting the progress of the disease. Amongst these is the Spitz-Holter valve operation which in various hands appears to arrest the condition in $70-90 \%$ of the cases. ${ }^{11,14}, 15$ Early diagnosis and accurate assessment of the cases is therefore now essential if the best results are to be obtained. A knowledge of the natural history of hydrocephalus is of very great importance both in deciding when to recommend a case for surgical treatment and later in assessing its results.

Hydrocephalus is, however, only a physical state, which has a number of anatomical causes. Each of these tends to run a separate and distinct clinical course, and have its own prognosis.

\section{Pathology}

Contrary to the general belief, hydrocephalus is more often acquired than truly congenital in origin. This fallacy has probably arisen because the condition so frequently develops within the first few months of life, sometimes without any definite dintecedent history.

Hydrocephalus, the accumulation of excessive amounts of cerebrospinal fluid within the cranial cavity, may result from overproduction, obstruc-
TABLE I

Causes of Hydrocephalus

Over-production of Choroid plexus papilloma and C.S.F.

Obstruction to the Within ventricular system:

C.S.F. pathway

\section{Defective absorption of ? Venous sinus thrombus. \\ C.S.F.} Foramina of Munro. Aqueduct: Exit foramina.

Subarachnoid space: Arnold-Chiari malformation.

Basal cistern block.

Outside C.N.S.:

Skull abnormalities.

tion of the cerebrospinal pathway, or failure of absorption of cerebrospinal fluid (Table I). Overproduction undoubtedly occurs in the comparatively rare cases of choroid plexus papilloma, ${ }^{7}$ though most of these are complicated by a coexistent basal cistern block. Failure to absorb fluid as a cause of hydrocephalus has not been well authenticated and it is usually possible to find an obstructive lesion as the cause of the condition in cases of dural venous sinus thrombosis in which this under-absorption is thought to occur.

Obstruction is by far the most important cause both numerically and pathologically, and is usually of malformative or inflammatory origin or often a combination of the two.

Spina bifida cystica, which occurs in one or two cases per 1,000 live births, is frequently associated with hydrocephalus and this accounts for nearly all the cases where the condition is due to malformation. Here the hydrocephalus may occa- o sionally be due to congenital aqueduct malformations, i.e. forking or stenosis. More frequently the Arnold-Chiari malformation of the hind brain, which is found in nearly all cases of myelocele, accounts for the hydrocephalus by obstruction of the basal cisterns due to overcrowding of the posterior fossa structures (Fig. I), or a block of the exit foramina which are displaced down the 


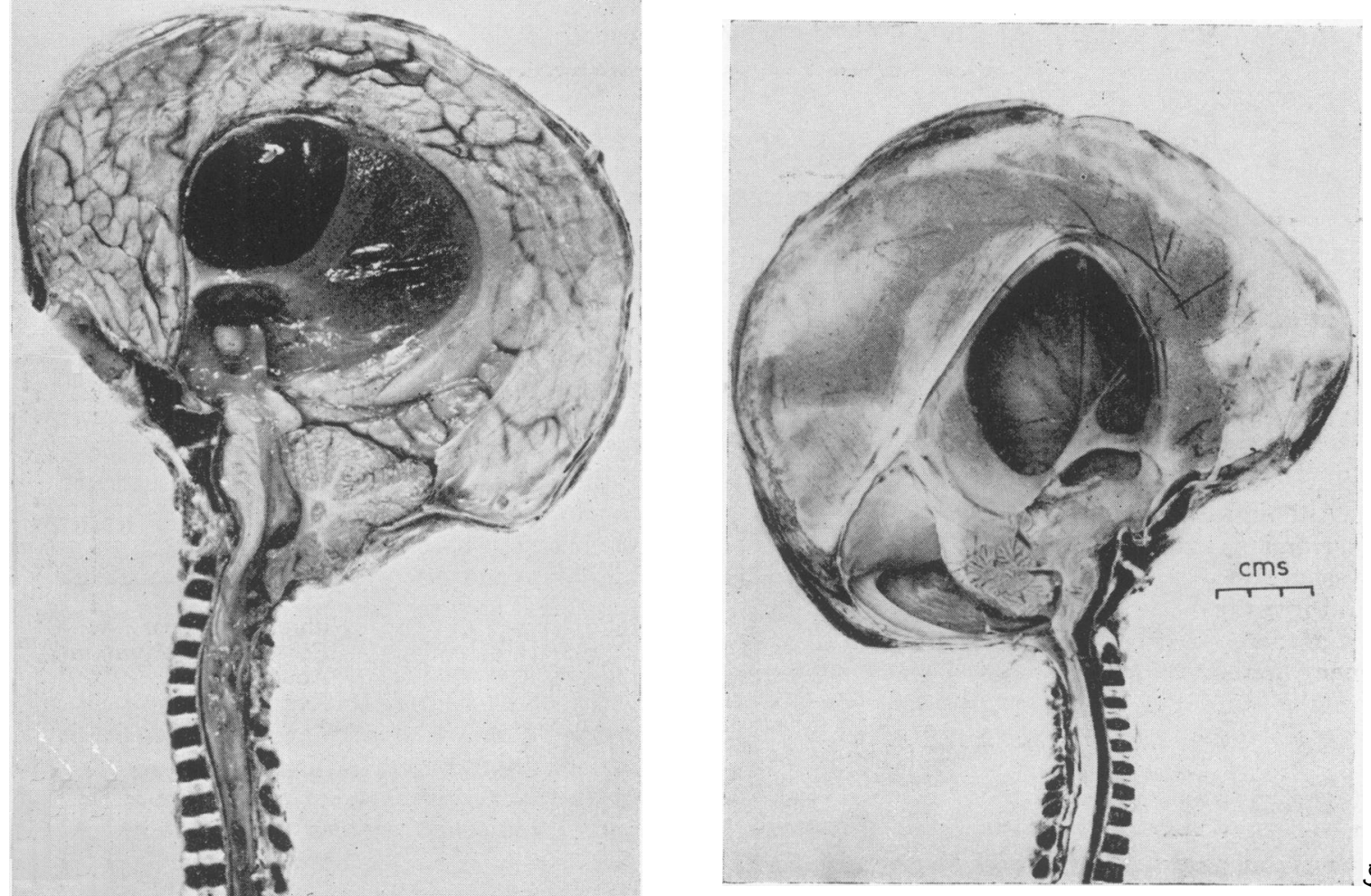

Fig. 2.-A hemisected skull of a case of basal cistern block. The lateral ventricle, seen through the fenestrated septum pellucidum, and the third ventricle are severely dilated. A terminal stenosis had occurred in the aqueduct (not shown in this? section). The cisterna magna is very grossly dilated, compressing the cerebellum.

spinal canal. Ascending infection from the raw spina bifida sac, which so very frequently occurs, may lead to inflammatory obstructive lesions superimposed upon what may already be an embarrassed cerebrospinal fluid circulation. Aqueduct malformations may rarely be found without association with spina bifida cystica.

Inflammatory lesions, apart from those superimposed upon malformations, form the other important, though smaller, group. Probably the commonest single cause of post-inflammatory hydrocephalus is extravasation of blood into the cerebrospinal fluid pathway, resulting from direct birth trauma or perinatal anoxia, so frequently seen in premature infants or, occasionally, from spontaneous subarachnoid haemorrhage or head injury in older children. Intracranial infection appears to be a rather less important cause. Frequently, however, there is no antecedent history of cerebral 'birth injury.' or infection, though in some" of "these" cases haemosiderin deposits in the meninges, found at post-mortem examination, suggests a ' traumatic' origin. In

FIG. I.-Severe hydrocephalus affecting the whole ventricular system, with hydromelia. An ArnoldChiari malformation is present with a cerebellar tongue and a largely intraspinal medulla, as well as a lumbo-sacral myelocoele, distorted by inflammatory changes. 


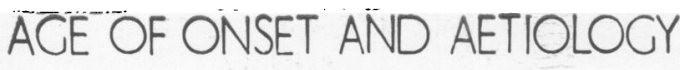

182 CASES

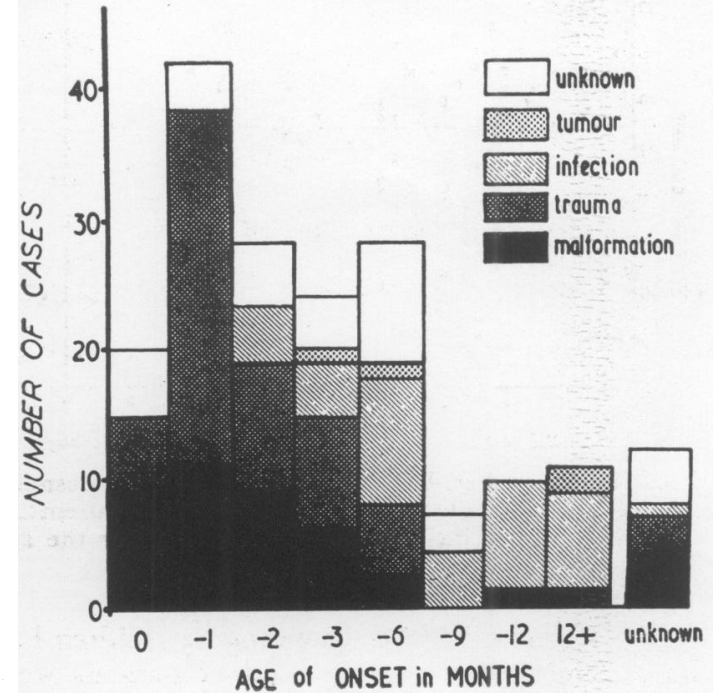

Fig. 3.-The age of onset of hydrocephalus in 182 cases.

nearly all these cases an occlusive fibrosis in the subarachnoid space leads to a basal cistern block (Fig. 2). Some cases are complicated by the block of the exit foramina of the fourth ventricle where the fibrosis has involved these orifices. The inflammatory agent often damages the vulnerable ependymal lining, and when this occurs in the narrow aqueduct, the subependymal gliosis which results may occlude the lumen, while in other instances blood clot or pus will cause the aqueduct block.

Tumours anywhere, within the cranium may also lead to obstruction of the cerebrospinal fluid pathway.

Fuller accounts of the pathology have been given elsewhere. ${ }^{9}, 12$

\section{Natural History}

Since hydrocephalus is a condition with a number of causes the disease is naturally not uniform in character. When due entirely to a congenital malformation, such as aqueduct stenosis or severe Arnold-Chiari malformation in association with spina bifida, head enlargement is usually present at birth or becomes apparent very soon afterwards, whereas if it results from 'birth haemorrhage' it is often not noticed for four to six weeks (Fig. 3). When the condition, associated with spina bifida cystica, is not present at birth but develops later due to a superimposed infection, it rarely does so later than the age of six months, as by then the spina bifida sac has usually fully epithelialized and infection becomes excluded.

Many cases progress rapidly with unremittin\$ head enlargement. Terminally, spasticity, vomit $\frac{0}{2}$ ing, pressure sores and occasionally blindness: develop. Death often occurs before the patient is a year old. The commonest immediate causes of death are cardio-respiratory failure, bronchoø pneumonia and intracranial infection, the latte especially in cases of spina bifida cystica.

Other cases may progress rapidly for a whilo and then stabilize, though not before the head. has become too large to be supported properly of before additional brain damage has occurred $\overrightarrow{\dot{\omega}}$ Either these cases are placed in an institution op the long-suffering families will nurse them witB their severe spasticity, mental defect, occasiona blindness and often complete helplessness. Sucliw tragedies are remembered and they probablys account for the general belief that used to be held by the medical profession, that few patientis with this condition survive, and that those who do are doomed to permanent institutional care $\frac{\text { o }}{-}$ For example, Ford, ${ }^{2}$ in his textbook on 'Diseases of the Nervous System in Infancy, Childhoo 5 and Adolescence,' agrees that in some childrets the disease seems to become arrested, but adds that in such cases the child goes through life more or less mentally defective. Holt and MacIntos, in their textbook on 'Paediatrics,' state that conf genital hydrocephalus may become arrestedôât any stage but go on to say that such an outcom? is rare. Clinicians who commonly deal with this problem are, however, well aware that natura arrest is quite frequent. Ingraham and Matsong briefly refer to it, but make no mention of it $\$$ incidence, and Jolly ${ }^{6}$ discusses its importance $\overrightarrow{0}$ On the other hand, Bucy ${ }^{1}$ put the spontaneous arrest rate at up to $10 \%$ and Macnab ${ }^{11}$ reports Ig cases of spontaneous remission amongst his. I 60 patients. A much higher arrest rate was first indicated by Forrest, Laurence and Macnab who found that $30 \%$ of their 70 patients seen io 1954 and 1955 had arrested spontaneously.

In a more recent investigation largely publishe $\$$ as a preliminary communication, ${ }^{8}$ the author examined this problem further by following up a large unselected series of hydrocephalic patientis seen over a period of 20 years by Mr. Wyllie. McKissock at the Hospital for Sick Children or Great Ormond Street, and the Atkinson-Morley Hospital, Wimbledon. This surgeon felt unconD vinced of the merits of any form of surgery then available and therefore very rarely operated upote these cases. The results were wholly unexpectedo as of the 182 patients 81 were found to be alive with the hydrocephalus arrested spontaneously:A further three were not traced, but the available 
TABLE II

The Natural History of Hydrocephalus (I82 patients)

No. of Cases

Alive:

$$
\begin{aligned}
& \text { Hydrocephalus arrested } \\
& \text { Untraced (presumed alive) } \quad \ldots \quad \ldots \quad 3\} 46.2 \%
\end{aligned}
$$

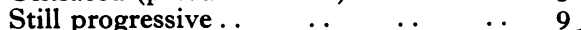

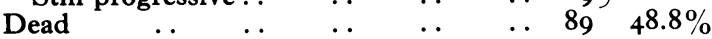

TABle III

Intelligence Assessments

(8I patients)

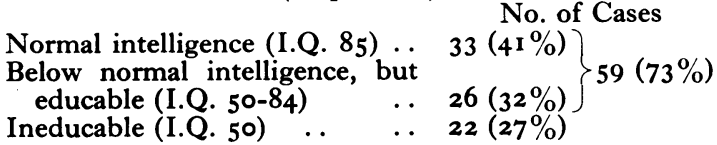

INTELLIGENCE TESTS

81 CASES AVERAGE 1.Q. 69.7

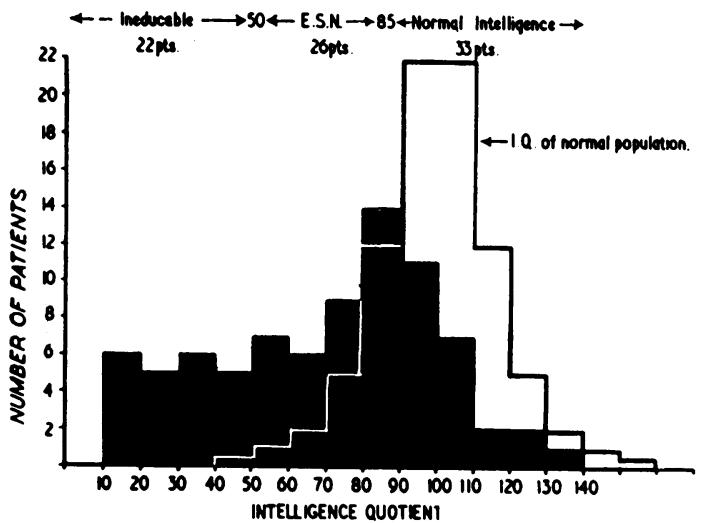

FIG. 4.-Distribution of intelligence-assessment results in 81 cases (average I.Q. 69.7). The superimposed line represents the distribution of the same number of test results in a normal population.

evidence suggested that they were still alive with the disease also arrested; 89 patients had died and in nine, all then under the age of five years, the condition was still progressing (Table 2). The intellectual performance of the survivors and their physical condition were further investigated as upon these factors depends their future place in the community. This yielded further surprising results.

It was possible to obtain intelligence assessments on all the $8 \mathrm{I}$ patients and it was found that 33 had an I.Q. of 85 or above. A further 26 patients were below normal intelligence but educable and the remaining 22 were ineducable (Table 3). The average intelligence of the whole group was just below 70 with a distribution which was approximately normal (Fig. 4), but a standard deviation of about twice the normal. The Schonell reading test ${ }^{13}$ was used on 21 of the 59 educable children who had an average chronological age of
HEAD SIZE, PHYSICAL STATE AND I.Q

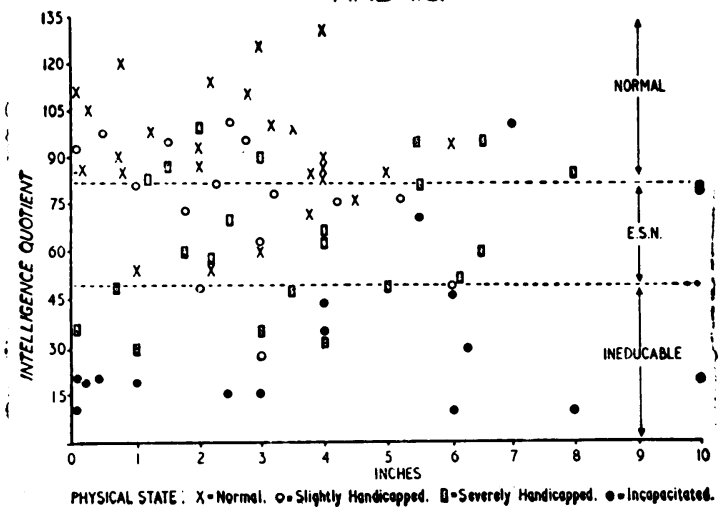

FIG. 5.-The distribution of intelligence assessment results when plotted against the head measurement, measured in inches, above the normal for the age and sex.

I I years 5 months (the remaining 23 children had not yet reached school age, and 15 patients were not tested). The average reading age of the $2 \mathrm{I}$ children was 9 years 10 months. This suggests that these children were not only educable but were being educated.

Unfortunately, some of these patients suffer from physical disability in addition. The severesto hydrocephalus is, however, not always associated with the severest physical handicap. Of the survivors, 27 (i.e. one-third) suffered no physical disability at all. A further I 5 cases did suffer disability such as slight spasticity, a squint, perhaps slight imbalance, which did not prevent them from getting about unaided; most of them were not forced to attend special schools on account of their physical handicap alone. 22 cases were severely handicapped and always had to attend special schools or even in some instances had to receive home schooling. Only 17 cases were completely bedridden and were generally confined to institutions. Altogether 25 children had normal intelligence, i.e. I.Q. 85 or above with negligible or no physical handicap.

Relationships were looked for between intelligence and other features. It was found that there was no relationship whatsoever between intelligence quotient and head size (Fig. 5). Further, in 37 cases where reliable information on the thickness of the cerebral mantle was available, it was found that this could not be related to intelligence (Fig. 6). For example, one child with a cortical thickness of $0.5 \mathrm{~cm}$., estimated from a ventriculogram, had an I.Q. of 85 and another case had one of roo (Fig. 7). Indeed, some of the most severely mentally handicapped patients had a thick but presumably damaged 


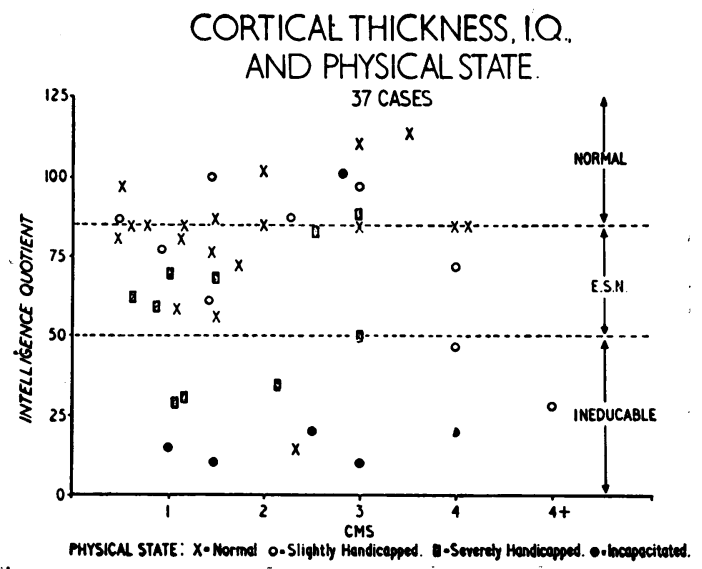

FIG. 6.-The distribution of intelligence assessment results when plotted against the thickness of the cerebral mantle in the 37 patients in whom reliable encephalographs were available.

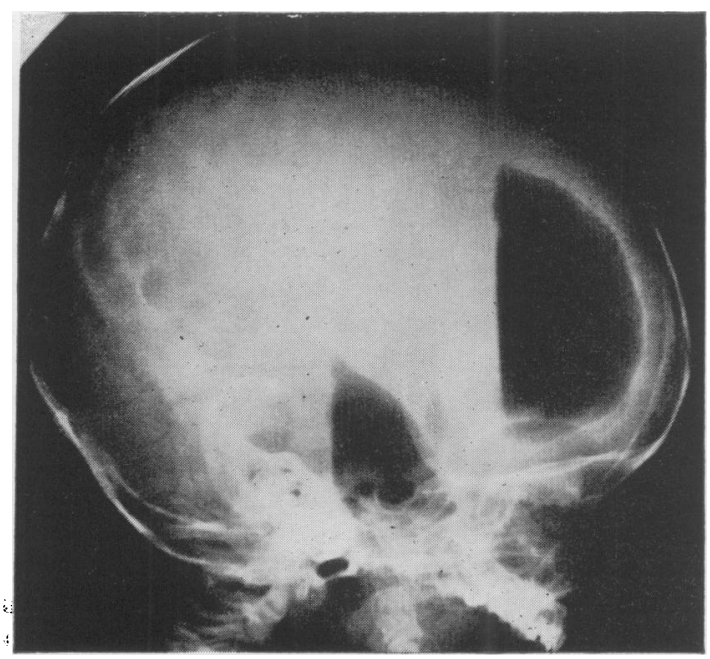

FiG. 7.-A ventriculogram of a case of severe hydrocephalus with a 'cortex' of less than I cm. thick. The I.Q. was 88 and there was no physical disability.

pallium, damage probably produced by the same agent that led to the hydrocephalus. This suggests that the oft-quoted minimum of $2 \mathrm{~cm}$. of ' cortex' required for normal intelligence should be revised.

A low correlation existed between the I.Q. and age, the scores tending to rise slightly in the older children. The reasons for this may be twofold. Firstly, younger children tend to be more deprived as they will have spent a greater proportion of their life in institutions. Secondly, with age these patients may overcome some of their physical handicap and will therefore be able to have more intelligence available for measurement by the tests which were employed.

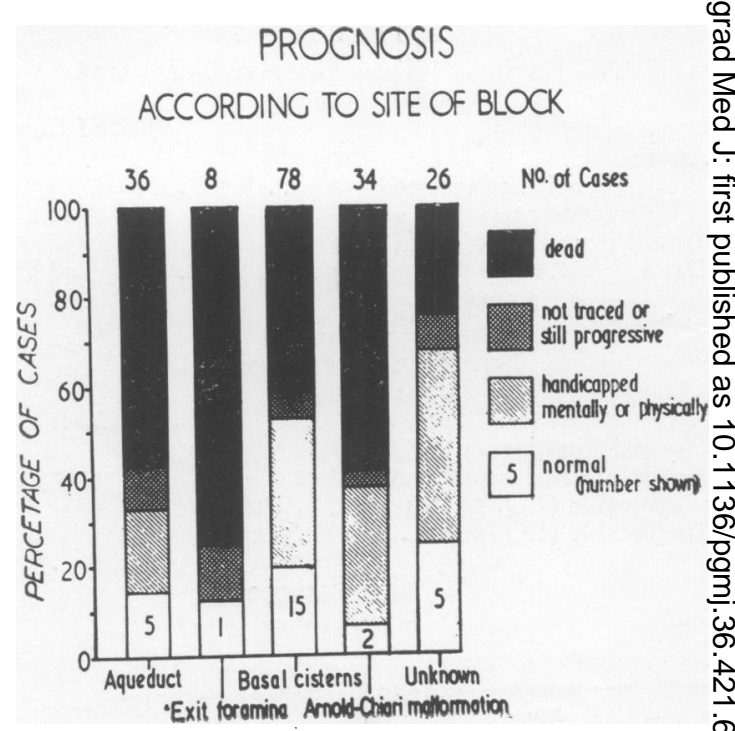

FIG. 8.-Prognosis regarding handicap and survivalo according to site of block.

There was a close correlation between physical $\vec{z}$ disability and intelligence quotient, those whoo were severely handicapped tending to score very much lower. This was partly caused by failure of the tests available to measure te remaining mental ability in the presence of severeo physical handicap, as most of the tests require ato least some physical skill. Severely handicappe्did children also have difficulty in communicating with others of the same age either because they are not able to play freely with others, isolated ato home or in an institution, or because they may lack one or more of the five senses. Older children may require so much hospital treatment for cor-을 rection of deformities, that schooling suffers and so they do not receive the same educationalof opportunities as their less physically handicapped contemporaries.

The prognosis of the whole group seems to be் that should a hydrocephalic child survive, to. arrest spontaneously, for which he has a $46 \%$ o chance, he then has a $75 \%$ chance of being educable and a $57 \%$ chance of being taughto (apart from his physical handicap) in a school for normal children.

Hydrocephalus has, however, a number of different causes and each group has a different prognosis. Unfortunately, the individual aetio- 0 logical groups in this investigation were too small to draw definite conclusions, but an attempt waso made to compare them. It appeared that cases with a basal cistern block or those in which the site of the block is unknown, being due to eitheren an unknown aetiological agent or infection, seemedo to have the best outlook (Figs. 8 and 9). On the 


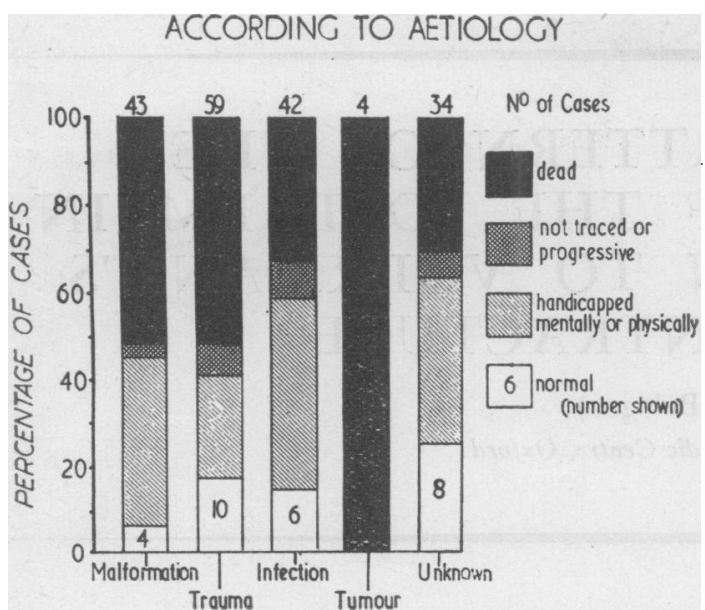

FIG. 9.-Prognosis regarding handicap and survival according to aetiology.

other hand, cases where the hydrocephalus was due to malformation in the aqueduct or in the hind brain (Arnold-Chiari malformation) seemed to carry the worst prognosis.

Unfortunately, some cases after spontaneous arrest has taken place may, months or even years later, become progressive once more. In other instances an acute episode of intracranial hypertension may kill the patient within a very short time. Such events may be precipitated by minor head injury or some infection. In other instances no precipitating cause can be discovered. These patients then, although the progress of the hydrocephalus may have arrested, are never quite free from danger.

\section{Conclusions}

Although some of the mental and physical handicap of hydrocephalic patients is due to ' cortical ' thinning and distortion of nerve tracks, much of the deficit is due to associated malformations and to parenchymal brain damage caused by the lesion that originally led to the hydrocephalus, such as infection and perinatal anoxia. The great importance of the interrelationship of the physical and mental ability cannot be stressed too much, for a great deal of the apparent mental handicap in these patients is caused by associated severe physical disability, some of which may be correctable by careful training and education and by surgery.

The series upon which the investigation into the natural history of hydrocephalus was based was not entirely representative of hydrocephalus in the general population as many of the most severely and the mildly affected cases never reached this particular large children's hospital. Certain general conclusions can nevertheless be drawn from it. A much more hopeful prognosis is suggested, as an appreciable proportion of these children, whose outlook used to be regarded as completely hopeless without surgical treatment, are now growing up into useful citizens capable of earning their own livelihood.

Care must be exercised in recommending patients for surgery, especially those in whom the condition is at the point of becoming arrested and who may do well without it. It must be stressed, however, that in cases of progressive hydrocephalus much additional brain damage may be caused by waiting for spontaneous arrest to occur, especially when this may never take place. Even in a very slowly progressive disease, early and effective surgical intervention may possibly leave the patients with less brain damage than when the disease is allowed to run its natural course, even though the best surgery is not without its serious risks in this condition. Further work investigating this particular point, using a properly controlled series, is very urgently needed.

\section{Summary}

The pathology and natural history of hydrocephalus is discussed. A very much more hopeful prognosis is suggested by a $46 \%$ survival and a $73 \%$ educability rate of the survivors.

\section{Acknowledgments}

I wish to thank Mr. T. J. Cooke, Mr. Derek Martin and Mr. L. Williams for illustrations, and the editors of the Lancet and the Cerebral Palsy Bulletin for permission to use Fig. 4, and Figs. 5 and 6 respectively. Thanks are also due to the research committee of the Hospital for Sick Children which supported most of the work upon which this paper was based.

\section{REFERENCES}

I. BUCY, P. C. (1950), in 'Brennemann's Practice of Pediatrics, chap. 3. Prior: Hagerstown.

2. FORD, F. R. (1952), 'Diseases of the Nervous System in Infancy, Childhood and Adolescence,' p. 255. Charles C Thomas: Springfield, IIl.

3. FORREST, D. M., LAURENCE, K. M., and MACNAB G. H. (1957), Lancet, i, 1274.

4. HOLT, L. E., and McINTOSH, R. (1953), 'Pediatrics,' p. I053. Edward Appleton: New York.

5. INGRAHAM, F. D., and MATSON, D. D. (I954), 'Neurosurgery of Infancy and Childhood,' p. I17. Charles C Thomas: Springfield, Ill.

6. JOLLY, H. (1955), Proc. roy. Soc. Med., 48, 843.

7. KAHN, E. A., and LUROS, J. T. (1952), F. Neurosurg., 9, 59.

8. LAURENCE, K. M. (1958), Lancet, ii, I 152.

9. LAURENCE, K. M. (1959), Ann. roy. Coll. Surg. Engl., 24, 388.

Io. MACNAB, G. H. (1955), Proc. roy. Soc. Med. 48, 846.

11. MACNAB, G. H. (1959), F. Neurol. Neurosurg. Psychiat., 22, 84.

12. RUSSEL, D. S. (1949), 'Observations on the Pathology of Hydrocephalus,' Special Report, Medical Research Council, Ser. 265. London: H.M.S.O.

13. SCHONELI, F. J., and SCHONELL, F. E. (1952), 'Diagnostic and Attainment Testing,' 2nd edition. Edinburgh: Oliver and Boyd.

14. SPITZ, E. B. (1959), Pediat. Clin. N. Amer., 6, 1215.

15. ZACHÁRY, R. B., and LAUBER, J. (I960), Personal communication. 